\title{
PERAMALAN NILAI TUKAR DOLAR SINGAPURA (SGD) TERHADAP DOLAR AMERIKA (USD) DENGAN MODEL ARIMA DAN GARCH
}

\author{
FATIHATUR RAMADHANI, MAIYASTRI, YUDIANTRI ASDI \\ Program Studi Matematika, \\ Fakultas Matematika dan Ilmu Pengetahuan Alam, Universitas Andalas, \\ Kampus UNAND Limau Manis Padang, Indonesia, \\ email : fatihaturramadhani@gmail.com
}

\begin{abstract}
Abstrak. Uang memegang peranan penting dalam perekonomian setiap negara. Namun nilai tukar mata uang dapat berubah-ubah dari waktu ke waktu. Naik turunnya nilai tukar uang di pasar uang dapat mempengaruhi tingkat kestabilan ekonomi suatu negara. Salah satu cara untuk melihat keadaan ekonomi suatu negara dapat dilakukan dengan memodelkan nilai tukar mata uang negara tersebut. Salah satu model untuk memodelkan rataan adalah model ARIMA. Sedangkan untuk memodelkan besarnya volatilitas menggunakan model GARCH. Setelah itu ditentukan nilai resiko kerugian maksimum dengan menggunakan Value at Risk. Pada penelitian ini dianalisis model ARIMA dan GARCH pada data nilai tukar mata uang Dolar Singapura (SGD) terhadap Dolar Amerika (USD). Diperoleh model terbaik adalah $\operatorname{ARIMA}(0,1,1)$ dan $\operatorname{GARCH}(1,1)$. Berdasarkan estimasi VaR diperoleh bahwa dengan taraf kepercayaan 90\% kerugian maksimum yang mungkin akan dialami dengan menginvestasikan uang sebesar US $\$ 300.000$ adalah sebesar US $\$ 2881.977$.
\end{abstract}

Kata Kunci: Model ARIMA, Model GARCH, Value at Risk

\section{PENDAHULUAN}

Uang memegang peranan penting dalam perekonomian setiap negara. Aktifitas ekonomi yang dapat dilakukan suatu negara dengan menggunakan uang adalah perdagangan. Untuk melakukan kegiatan tersebut, suatu negara harus memiliki mata uang yang sesuai dengan negara yang ditujunya sehingga diperlukan kegiatan menukar uang. Tingkat harga yang disepakati kedua negara untuk nilai tukar uang tersebut dinamakan kurs atau exchange rate. Naik turunnya nilai tukar mata uang di pasar uang menunjukkan besarnya volatilitas yang terjadi pada mata uang suatu negara dengan negara lain.

Perdagangan nilai tukar uang sudah dilakukan berbagai negara di dunia. Termasuk salah satu wilayah di Asia yaitu Asia Tenggara. Singapura dan merupakan negara yang berada di kawasan Asia Tenggara. Singapura merupakan pusat keuangan terdepan keempat di dunia dan sebuah negara yang memegang peranan penting dalam perdagangan dan keuangan internasional. Karena hal tersebut maka akan dilihat bagaimana model nilai tukar mata uang Dolar Singapura.

Analisis data yang digunakan untuk nilai tukar uang dan besarnya volatilitas adalah analisis time series. Model peramalan analisis time series yang dapat digu- 
nakan untuk meramalkan nilai tukar uang adalah model ARIMA (Autoregressive Integrated Moving Average) dan untuk menganalisis besarnya volatilitas nilai tukar uang digunakan model GARCH (Generalized Autoregressive Conditional Heteroscedasticity) yang diperkenalkan oleh Bollerslev tahun 1986.

\section{KAJIAN PUSTAKA}

\subsection{Model Deret Waktu}

(1) Model Autoregressive (AR).

Bentuk umum model AR orde ke-p atau AR(p) adalah

$$
X_{t}=\phi_{1} X_{t-1}+\phi_{2} X_{t-2}+\cdots+\phi_{p} X_{t-p}+\varepsilon_{t}
$$

dengan:

$$
\begin{aligned}
X_{t} & : \text { nilai pengamatan pada waktu ke-t } \\
\phi_{i} & : \text { parameter ke-i, } i=1,2, \cdots, p \\
\varepsilon_{t} & : \text { nilai error pada saat t, dengan } \varepsilon_{t} \sim W N\left(0, \sigma^{2}\right) .
\end{aligned}
$$

(2) Model Moving Average (MA).

Bentuk umum model MA orde ke-q atau MA(q) adalah

$$
X_{t}=\varepsilon_{t}-\theta_{1} \varepsilon_{t-1}-\theta_{t-2} \varepsilon_{t-2}-\cdots-\theta_{q} \varepsilon_{t-q}
$$

dengan:

$$
\begin{aligned}
& \theta_{i}: \text { koefisien moving average, } i=1,2, \cdots, p \\
& \varepsilon_{t}: \text { nilai error pada saat t, dengan } \varepsilon_{t} \sim W N\left(0, \sigma^{2}\right) .
\end{aligned}
$$

(3) Model ARMA (Autoregressive Moving Average)

Bentuk umum model ARMA(p,q) adalah

$$
X_{t}=\phi_{1} X_{t-1}+\phi_{2} X_{t-2}+\cdots+\phi_{p} X_{t-p}+\varepsilon_{t}-\theta_{1} \varepsilon_{t-1}-\theta_{t-2} \varepsilon_{t-2}-\cdots-\theta_{q} \varepsilon_{t-q} .
$$

(4) Model ARIMA (Autoregressive Integreted Moving Average)

Bentuk umum model ARIMA(p,d,q) adalah

$$
\nabla^{d} X_{t}=\phi_{1} X_{t-1}+\phi_{2} X_{t-2}+\cdots+\phi_{p} X_{t-p}+\varepsilon_{t}-\theta_{1} \varepsilon_{t-1}-\theta_{t-2} \varepsilon_{t-2}-\cdots-\theta_{q} \varepsilon_{t-q}
$$

\subsection{Return}

Return adalah tingkat keuntungan yang diperoleh investor. Cara menghitung return adalah

$$
r_{t}=\ln \left(\frac{X_{t}}{X_{t-1}}\right)
$$

dengan:

$r_{t}:$ return pada waktu ke-t,

$X_{t}$ : harga nilai tukar mata uang pada waktu ke-t

$X_{t-1}$ : harga nilai tukar mata uang pada waktu ke- t-1 
112 Fatihatur Ramadhani dkk.

\subsection{Model ARCH-GARCH}

Dengan memanfaatkan heterokedastisitas dalam residu yang tepat, akan diperoleh varians yang lebih efisien. Model dengan varians yang lebih efisien ini dikenal dengan nama Autoregressive Conditional Heteroscedasticity (ARCH) dan Generalized Autoregressive Conditional Heteroscedasticity (GARCH).

Secara umum, model $\mathrm{ARCH}(\mathrm{q})$ adalah sebagai berikut.

$$
\sigma_{t}^{2}=\alpha_{0}+\alpha_{1} \varepsilon_{t-1}^{2}+\cdots+\alpha_{q} \varepsilon_{t-q}^{2},
$$

dengan $e_{t} \sim N(0,1) \alpha_{0}>\alpha_{i}>0, i=1,2, \cdots, q$.

Secara umum, model $\operatorname{GARCH}(\mathrm{p}, \mathrm{q})$ didefinisikan sebagai berikut.

$$
\sigma_{t}^{2}=\alpha_{0}+\alpha_{1} \varepsilon_{t-1}^{2}+\cdots+\beta_{1} \sigma_{t-1}^{2}+\cdots+\beta_{p} \sigma_{t-p}^{2}
$$

dengan $\alpha_{0}>0, \alpha_{i} \leq 0, i=1,2, \cdots, q, \beta_{j} \leq 0, j=1,2, \cdots, p,\left(\sum_{i=1}^{q} \beta_{i}+\right.$ $\left.\sum_{j=1}^{p} \beta_{i}\right)<1$.

\subsection{Value at Risk}

Value at Risk (VaR) merupakan resiko maksimum yang akan didapatkan dari pada suatu periode waktu tertentu pada kondisi pasar normal dengan tingkat kepercayaan tertentu. Rumus VaR pada tingkat kepercayaan $1-\alpha$ adalah

$$
\operatorname{VaR}=\left(\hat{r}_{t}-z_{\alpha} \hat{\sigma}_{t}\right) \times W_{0} .
$$

\section{Data dan Hasil}

\subsection{Pemodelan Nilai Tukar SGD dengan Model ARIMA}

Data nilai tukar yang akan dianalisis adalah data nilai tukar mata uang Dolar Singapura (SGD) terhadap Dolar Amerika (USD) dengan periode mingguan dari tanggal 1 Januari 2007 sampai 26 September 2016. Langkah awal yang dilakukan adalah memplot data untuk melihat kestasionerannya, seperti pada Gambar 1.

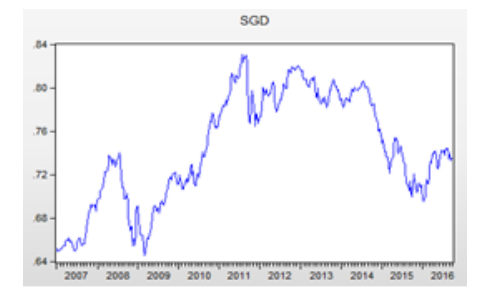

Gambar 1. Plot Data Nilai Tukar SGD terhadap USD

Dari plot data terlihat bahwa data mengalami kenaikan dan penurunan. Hal ini menunjukkan bahwa data tidak stasioner. Untuk melihat apakah data sudah stasioner terhadap varian dilihat dari transformasi Box-Cox. Pada pengujian BoxCox plot diperoleh $\lambda$ sebesar satu. Ini berarti data sudah stasioner terhadap varian. 
Karena pada plot data menunjukkan bahwa data tidak stasioner, ini menunjukkan bahwa data tidak stasioner terhadap mean sehingga harus dilakukan proses pembedaan (differencing). Pada Gambar 2 diberikan plot hasil pembedaan.

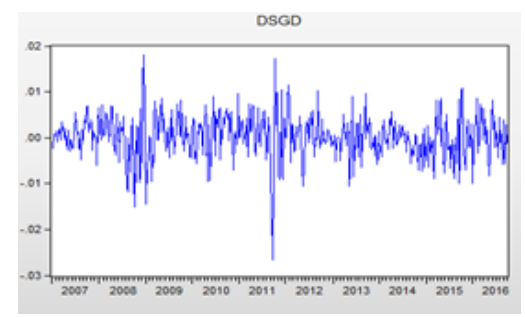

Gambar 2. Data Pembedaan Pertama Nilai Tukar SGD terhadap USD

Plot data menunjukkan bahwa data telah berda di sekitar nilai tengah, yang berarti data sudah stasioner terhadap mean. Untuk membuktikan dilakukan uji ADF terhadap data yang telah dilakukan pembedaan pertama. Diperoleh nilai ADF sebesar - 15.60213 dengan nilai kritisnya sebesar -2.569751. berdasarkan uji ADF diperoleh nilai statistik ADF lebih kecil daripada nilai kritisnya. Ini berarti data sudah stasioner terhadap mean.

Selanjutnya akan diidentifikasi model ARIMA yang cocok dengan melihat korelogram ACF dan PACF. Berdasarkan korelogram diperoleh koefisien ACF dan PACF signifikan pada lag 1. Dengan demikian, kemungkinan model untuk kurs SGD terhadap USD adalah $\operatorname{ARIMA}(1,1,0), \operatorname{ARIMA}(1,1,1)$, dan $\operatorname{ARIMA}(0,1,1)$. Setelah kemungkinan model diperoleh maka akan diestimasi parameter model. Pada Tabel 1 diberikan hasil estimasi model ARIMA.

Tabel 1. Estimasi Parameter Model ARIMA kurs SGD terhadap USD

\begin{tabular}{|c|c|c|c|}
\hline & ARIMA (1,1,0) & ARIMA (1,1,1) & ARIMA $(0,1,1)$ \\
\hline$\phi_{1}$ & 0.350530 & 0.188726 & - \\
$(p$-value $)$ & $(0.0000)$ & $(0.1172)$ & \\
\hline$\theta_{1}$ & - & 0.187052 & 0.352479 \\
$(p$-value $)$ & & $(0.1209)$ & $(0.0000)$ \\
\hline
\end{tabular}

Dari hasil estimasi parameter model pada Tabel 1 diperoleh bahwa terdapat model yang tidak layak masuk ke dalam kandidat model ARIMA karena terdapat parameter yang probabilitasnya lebih besar dari taraf nyata $\alpha=10 \%$. Sehingga kandidat model yang layak masuk adalah ARIMA $(1,1,0)$ dan $\operatorname{ARIMA}(0,1,1)$.

Selanjutnya dari masing-masing kandidat model akan dipilih model terbaik dengan membandingkan nilai AIC, BIC, dan HQ pada masing-masing model, seperti dapat dilihat pada Tabel 2 .

Dari analisis yang telah dilakukan pada semua kemungkinan model diperoleh model terbaik untuk kurs Dolar Singapura terhadap Dolar Amerika adalah 
114 Fatihatur Ramadhani dkk.

Tabel 2. Perbandingan Nilai Berdasarkan Model Kurs SGD terhadap USD

\begin{tabular}{|c|c|c|c|c|}
\hline Model & AIC & BIC & HQ & Peringkat \\
\hline ARIMA $(1,1,0)$ & -8.022576 & -8.014236 & -8.019305 & 2 \\
\hline ARIMA $(0,1,1)$ & -8.024677 & -8.016350 & -8.021412 & 1 \\
\hline
\end{tabular}

$\operatorname{ARIMA}(0,1,1)$ yaitu

$$
\nabla^{1} X_{t}=-0.352479 \varepsilon_{t-1}+\varepsilon_{t} .
$$

Selanjutnya pada Tabel 3 diberikan peramalan nilai tukar mata uang Dolar Singapura terhadap Dolar Amerika dengan model terbaik.

Tabel 3. Peramalan Nilai Tukar Kurs SGD terhadap USD

\begin{tabular}{|l|c|c|c|}
\hline Tanggal & Peramalan & Aktual & Eror \\
\hline 03 Oktober 2016 & 0.733049 & 0.729347 & 0.003702 \\
\hline 10 Oktober 2016 & 0.733208 & 0.722519 & 0.010689 \\
\hline 17 Oktober 2016 & 0.733366 & 0.718899 & 0.014467 \\
\hline 24 Oktober 2016 & 0.733525 & 0.718064 & 0.015461 \\
\hline 31 Oktober 2016 & 0.733683 & 0.721157 & 0.012526 \\
\hline 7 November 2016 & 0.733842 & 0.713386 & 0.020474 \\
\hline 14 November 2016 & 0.734 & 0.704141 & 0.029859 \\
\hline 21 November 2016 & 0.734159 & 0.700166 & 0.033993 \\
\hline 28 November 2016 & 0.734317 & 0.70184 & 0.032477 \\
\hline 5 Desember 2016 & 0.734476 & 0.701927 & 0.032549 \\
\hline 12 Desember 2016 & 0.734634 & 0.696089 & 0.038545 \\
\hline 19 Desember 2016 & 0.734792 & 0.691019 & 0.043773 \\
\hline 26 Desember 2016 & 0.734951 & 0.690338 & 0.044613 \\
\hline 2 Januari 2017 & 0.735109 & 0.693667 & 0.041442 \\
\hline 9 Januari 2017 & 0.735268 & 0.698408 & 0.03686 \\
\hline 16 Januari 2017 & 0.735426 & & \\
\hline 23 Januari 2017 & 0.735585 & & \\
\hline 30 Januari 2017 & 0.735743 & & \\
\hline 6 Februari 2017 & 0.735902 & & \\
\hline 13 Februari 2017 & 0.73606 & & \\
\hline
\end{tabular}

\subsection{Pemodelan Nilai Tukar SGD terhadap USD dengan Model GARCH}

Langkah pertama adalah menghitung return pada data. Setelah data return diperoleh maka plot data untuk melihat kestasionerannya, seperti pada Gambar 3.

Pada plot data diperoleh bahwa data berfluktuasi disekitar garis nol sehingga dapat dilihat bahwa data telah stasioner. Hal tersebut dapat dibuktikan dengan 


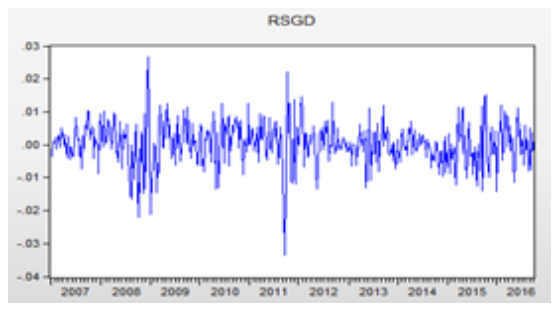

Gambar 3. Plot Data Return Nilai Tukar SGD terhadap USD

melakukan uji ADF. Dari uji ADF diperoleh bahwa nilai statistik uji ADF -15.69289 lebih kecil dari daripada nilai kritisnya -2.569751. disimpulkan bahwa data telah stasioner.

Selanjutnya akan ditentukan model rataan return dengan korelogram ACF dan PACF. Berdasarkan korelogram diperoleh ACF dan PACF mengalami penurunan drastis pada lag pertama sehingga kemungkinan model untuk kurs SGD terhadap USD adalah $\operatorname{ARMA}(0,1), \operatorname{ARMA}(1,1)$ dan $\operatorname{ARMA}(1,0)$.

Setelah kemungkinan model diperoleh maka akan diestimasi parameter model. Pada Tabel 4 diberikan hasil estimasi model ARIMA.

Tabel 4. Estimasi Parameter Model Rataan Return kurs SGD terhadap USD

\begin{tabular}{|c|c|c|c|}
\hline & ARMA(1,0) & ARMA(1,1) & ARMA(0,1) \\
\hline$\phi_{1}$ & 0.345630 & 0.180064 & - \\
$p$-value & $(0.0000)$ & $(0.1407)$ & \\
\hline$\theta_{1}$ & & 0.190124 & 0.349966 \\
p-value & & $(0.1196)$ & $(0.0000)$ \\
\hline AIC & -7.409752 & -7.411061 & -7.412165 \\
\hline BIC & -7.401412 & -7.394381 & -7.403837 \\
\hline HQ & -7.406481 & -7.404520 & -7.408899 \\
\hline Peringkat & 2 & Tidak signifikan pada $\phi_{1}$ dan $\theta_{1}$ & 1 \\
\hline
\end{tabular}

Dari Tabel 4 diperoleh model terbaik untuk rataan return adalah $\operatorname{ARMA}(0,1)$ yaitu

$$
r_{t}=-0.349966 \varepsilon_{t-1}+\varepsilon_{t} .
$$

Selanjutnya akan diperiksa apakah terdapat efek ARCH pada sisaan dengan menggunakan uji ARCH-LM. Pada uji ARCH-LM diperoleh bahwa nilai probabilitas dari chi-square untuk model rataan nilai tukar Dolar Singapura terhadap Dolar Amerika sebesar 0.0000. Ini berarti nilai probabilitas chi-square untuk model rataan lebih kecil daripada nilai $\alpha=10 \%$ yang menunjukkan bahwa ada pengaruh ARCH pada sisaan model.

Selanjutnya akan diidentifikasi orde dari model ARCH/GARCH. Model yang akan diduga hanya model $\operatorname{GARCH}(1,1), \operatorname{GARCH}(1,2)$, dan $\operatorname{GARCH}(2,1)$ karena 
pendugaan model diambil dari lag terkecil yaitu lag 1 dan lag 2. Pada Tabel 5 diberikan rangkuman hasil estimasi parameter terhadap kemungkinan model GARCH.

Tabel 5. Estimasi Model GARCH untuk Nilai Tukar SGD terhadap USD

\begin{tabular}{|c|c|c|c|}
\hline & GARCH $(1,1)$ & GARCH $(2,1)$ & GARCH $(1,2)$ \\
\hline $\mathrm{C}$ & $1.47 \times 10^{-6}$ & $2.16 \times 10^{-6}$ & $1.41 \times 10^{-6}$ \\
$p$-value & $(0.0418)$ & $(0.0338)$ & $(0.0499)$ \\
\hline$\alpha_{1}$ & 0.149945 & 0.204213 & 0.175378 \\
$p$-value & $(0.0000)$ & $(0.0000)$ & -0.037572 \\
\hline$\alpha_{2}$ & - & - & $(0.5383)$ \\
$p$-value & & 0.281727 & 0.825867 \\
\hline$\beta_{1}$ & 0.813093 & $(0.1931)$ & $(0.0000)$ \\
$p$-value & $(0.0000)$ & 0.457225 & - \\
\hline$\beta_{2}$ & - & $(0.0228)$ & -7.585187 \\
$p$-value & & -7.587891 & -7.543549 \\
\hline AIC & -7.588377 & -7.546253 & -7.568860 \\
\hline BIC & -7.555066 & -7.571563 & Ada koefisien negatif pada $\alpha_{2}$ \\
\hline HQ & -7.575315 & Tidak signifikan pada $\beta_{1}$ & \\
\hline Peringkat & 1 & & \\
\hline
\end{tabular}

Berdasarkan Tabel 5 diperoleh model terbaik untuk peramalan volatilitas nilai tukar Dolar Singapura terhadap Dolar Amerika adalah GARCH $(1,1)$.

$$
\begin{aligned}
r_{t} & =\varepsilon_{t}-0.369610 \varepsilon_{t-1}, \\
\sigma_{t}^{2} & =0.00000147+0.149945 \varepsilon_{t-1}^{2}+0.813093 \sigma_{t-1}^{2} .
\end{aligned}
$$

Setelah didapat model terbaik maka dilakukan uji asumsi sisaan untuk model terbaik. Pada model GARCH(1,1) kurs SGD dengan $\alpha=10 \%$ diperoleh bahwa sisaan tidak terdapat autokorelasi, sisaan tidak menyebar normal dan data bersifat homokedastisitas.

Selanjutnya akan ditentukan peramalan volatilitas menggunakan model GARCH terbaik dan dihitung VaR dari ramalan return dan volatilitas.

Pada Tabel 6 terlihat bahwa nilai ramalan return cenderung stabil dan nilai ramalan ragam serta volatilitasnya semakin besar. Karena nilai volatilitas semakin tinggi mengakibatkan Value at Risk juga tinggi yang artinya resiko berinvestasi akan semakin tinggi. Namun kenaikan nilai resiko pada mata uang Dolar Singapura naik secara bertahap yang berarti keadaan ekonomi negara Singapura cenderung stabil.

\section{Kesimpulan}

Model ARIMA terbaik untuk kurs SGD adalah ARIMA $(0,1,1)$ dan model GARCH terbaik adalah GARCH(1,1). Dari nilai peramlan ARIMA dan VaR yang telah 
Tabel 6. Nilai Ramalan Ragam dan Volatilitas Kurs SGD terhadap USD

\begin{tabular}{|l|c|c|c|c|}
\hline Tanggal & $\begin{array}{c}\text { Ramalan } \\
\text { Return }\end{array}$ & $\begin{array}{c}\text { Ramalan } \\
\text { Ragam }\end{array}$ & $\begin{array}{c}\text { Ramalan } \\
\text { Volatilitas }\end{array}$ & VaR SGD \\
\hline 03 Oktober 2016 & -0.001673 & 0.0000380 & 0.006174 & 2881.977 \\
\hline 10 Oktober 2016 & 0.000000 & 0.0000380 & 0.006575 & 2534.663 \\
\hline 17 Oktober 2016 & 0.000000 & 0.0000381 & 0.006580 & 2536.59 \\
\hline 24 Oktober 2016 & 0.000000 & 0.0000382 & 0.006586 & 2538.903 \\
\hline 31 Oktober 2016 & 0.000000 & 0.0000382 & 0.006591 & 2540.831 \\
\hline 7 November 2016 & 0.000000 & 0.0000383 & 0.00659659 & 2542.986 \\
\hline 14 November 2016 & 0.000000 & 0.0000383 & 0.00660158 & 2544.908 \\
\hline 21 November 2016 & 0.000000 & 0.0000384 & 0.00660637 & 2546.757 \\
\hline 28 November 2016 & 0.000000 & 0.0000385 & 0.00661099 & 2548.536 \\
\hline 5 Desember 2016 & 0.000000 & 0.0000385 & 0.00661543 & 2550.248 \\
\hline 12 Desember 2016 & 0.000000 & 0.0000386 & 0.0066197 & 2551.896 \\
\hline 19 Desember 2016 & 0.000000 & 0.0000386 & 0.00662382 & 2553.482 \\
\hline 26 Desember 2016 & 0.000000 & 0.0000387 & 0.00662778 & 2555.009 \\
\hline 2 Januari 2017 & 0.000000 & 0.0000387 & 0.00663159 & 2556.478 \\
\hline 9 Januari 2017 & 0.000000 & 0.0000387 & 0.00663526 & 2557.892 \\
\hline 16 Januari 2017 & 0.000000 & 0.0000388 & 0.00663879 & 2559.253 \\
\hline 23 Januari 2017 & 0.000000 & 0.0000388 & 0.00664219 & 2560.564 \\
\hline 30 Januari 2017 & 0.000000 & 0.0000389 & 0.00664546 & 2561.825 \\
\hline 6 Februari 2017 & 0.000000 & 0.0000389 & 0.00664861 & 2563.039 \\
\hline 13 Februari 2017 & 0.000000 & 0.0000389 & 0.00665164 & 2564.207 \\
\hline
\end{tabular}

diperoleh dapat dikatakan bahwa keadaan ekonomi negara Singapura cenderung stabil karena volatilitas yang diperoleh cukup kecil.

\section{Daftar Pustaka}

[1] Brockwell, P.J., dan R.A. Davis. 2002.Introduction to Time Series and Forecasting. Springer, New York.

[2] Enders, W. 1995. Applied Econometric Time Series. John Wiley \& Sons, New York.

[3] Rosadi, Dedi. 2012. Ekonometrika dan Analisis Runtun Waktu Terapan dengan EViews. Andi Offset, Yogyakarta.

[4] Tsay, R.S. 2002. Analysis of Financial Time Series. John Wiley \& Sons, Inc, New Jersey. 